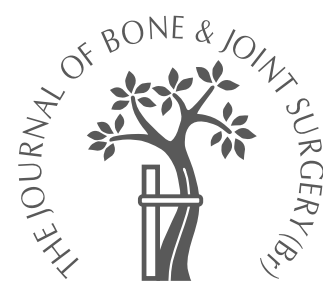

S. Glyn-Jones, H. S. Gill, P. McLardy-Smith, D. W. Murray

From the University of Oxford, England

- S. Glyn-Jones, MRCS, Specialist Registrar in Orthopaedics

H. S. Gill, DPhil, Senior Research Fellow

P. McLardy-Smith, FRCS,

Consultant Orthopaedic

Surgeon

D. W. Murray, FRCS,

Consultant Orthopaedic

Surgeon

Botnar Research Centre

University of Oxford

Nuffield Orthopaedic Centre, Windmill Road, Headington,

Oxford OX3 7LD, UK.

Correspondence should be sent to Dr H. S. Gill.

(C)2004 British Editorial Society of Bone and Joint Surgery

doi:10.1302/0301-620X.86B2. $14371 \$ 2.00$

$J$ Bone Joint Surg $[\mathrm{Br}]$ 2004;86-B:172-6.

Received 27 March 2003;

Accepted 5 June 2003

\title{
Roentgen stereophotogrammetric analysis of the Birmingham hip resurfacing arthroplasty
}

\author{
A TWO-YEAR STUDY
}

The Birmingham hip resurfacing (BHR) arthroplasty is a metal-on-metal prosthesis for which no medium- or long-term results have been published. Despite this, it is increasing in popularity as an alternative to stemmed prostheses for younger patients. Since the fixation of the socket is conventional, the major concern is long-term failure of the femoral component. This can be predicted by the use of roentgen stereophotogrammetric analysis (RSA). We have therefore undertaken such a study of the BHR femoral component over a period of two years.

Twenty patients (22 hips) underwent a standard BHR procedure. Migration of the femoral component was measured by RSA at intervals of three, six, 12 and 24 months. At 24 months the total three-dimensional migration of the head was $0.2 \mathrm{~mm}$. This was not statistically significant. Previous studies have shown that implants which loosen quickly have rapid early migration. Our results therefore suggest that the BHR femoral component is an inherently stable device which is likely to perform well in the long term.

Resurfacing arthroplasty was first performed by Charnley in the 1950s using polyethylene components. ${ }^{1}$ Over the decades resurfacing has gained a poor reputation because of its high failure rate owing to wear, aseptic loosening and fracture of the femoral neck. The procedure was virtually abandoned but has recently become popular once more.

The Birmingham hip resurfacing (BHR) arthroplasty (Midlands Medical Technologies (MMT) Ltd, Birmingham, UK) was introduced approximately five years ago and is now widely used in the UK. It is a metal-on-metal design with a cemented femoral component and an uncemented, hydroxyapatite-coated acetabular socket. The design is intended to overcome the past problems of aseptic loosening owing to polyethylene wear particles. The BHR is marketed by MMT as a reliable and desirable hip replacement for younger patients. The designers have such confidence in the device that they do not restrict the activities of patients after operation. The BHR is claimed to give a better symptomatic outcome than standard stemmed prostheses and is associated with a very low rate of dislocation. ${ }^{2}$ It is also claimed that the femoral component is easier to revise since smaller amounts of bone are lost. The company supports its claims with clinical data from 1700 operations in Birmingham involving the BHR and earlier designs over a period of ten years, during which only 17 complications arose. ${ }^{2}$ To date, however, there have been no medium- or long-term independent studies of this device. The results of the Birmingham clinical studies are far from conclusive as the design of the device has undergone five changes, three of which were fundamental, since the initial pilot study in 1991. A recent independent clinical study of 100 patients with a mean follow-up of 17 months showed similar results to those from Birmingham. $^{3}$

Some authors have suggested that the BHR may not be as successful as the manufacturers claim. Watanabe, Shiba and Matsuo ${ }^{4}$ performed a finite-element analysis study on the BHR and suggested that there was significant stress concentration around the base of the femoral component which could lead to fracture of the femoral neck. This was supported by a short clinical study by the same authors, ${ }^{4}$ who experienced three failures of 11 procedures because of fracture of the neck and loosening of the acetabular component.

This evidence, allied to the poor performance of resurfacing arthroplasties in the past, has done little to clarify the matter. The National Institute of Clinical Excellence (UK) cautiously recommended the BHR, but has called for more independent evidence to be collected. It states that of the few studies carried 
Table I. Details of the 24 patients who had resurfacing arthroplasty

\begin{tabular}{ll}
\hline Gender & \\
\hline Male & 14 \\
Female & 10 \\
Mean age in years (range) & 50 (26 to 60) \\
Mean weight in kilograms (range) & 80.7 (65 to 140) \\
Mean outer diameter of femoral component in $\mathrm{mm}$ & 60 \\
Mean outer diameter of acetabular component in $\mathrm{mm}$ & 54
\end{tabular}

out into modern resurfacing arthroplasties none has an adequate follow-up. An independent follow-up study of the current BHR design over a ten-year period is unlikely for some time and yet the safety of this device has still to be established.

Roentgen stereophotogrammetric analysis (RSA) is an ideal tool for the early assessment of new implants such as the BHR, since it can accurately measure the migration of a prosthesis relative to its host bone. It has been shown that rapid, early migration of a total hip replacement is associated with premature loosening. ${ }^{5-8}$ In this manner, the longevity of a prosthesis can be predicted within two years of implantation. All primary cemented and uncemented femoral stems migrate to some extent during the first year. Thereafter, their migration slows if they are not going to loosen. Kobayashi et $\mathrm{al}^{7}$ have suggested that an acceptable upper limit for the mean distal migration at two years is 0.4 $\mathrm{mm}$. Although this is not appropriate for all designs since, as the Exeter migrates $1.5 \mathrm{~mm}$ in the first two years, it is not an unreasonable benchmark for prostheses in which subsidence is not intended.

There are many potential problems which can occur with the BHR, including rare events such as tumours. However, the most common is likely to be aseptic loosening of the socket or stem. Since fixation of the socket of the BHR is relatively conventional, the problems which will occur are likely to be similar to those associated with conventional devices. By contrast, the performance of the stem is relatively unpredictable. The aim of our study therefore was to determine, by RSA, the migration of the BHR femoral component during the first two years after implantation, in the hope that this would predict its long-term outcome and provide a pattern of migration as a benchmark against which other resurfacing arthroplasties could be compared.

\section{Patients and Methods}

The operations and RSA measurements were carried out at the same centre. We recruited 24 patients with osteoarthritis from the routine waiting list. Two underwent bilateral procedures. Patients were excluded from the study if they were older than 60 years for women and 65 for men, in order to minimise the chances of a fracture of the femoral neck because of osteoporosis. There was no lower age limit for recruitment. Two surgeons (PM-S and DWM) performed the operations over a period of two years from November 1999. Each patient received a single dose of antibiotic before operation. All the procedures were per-
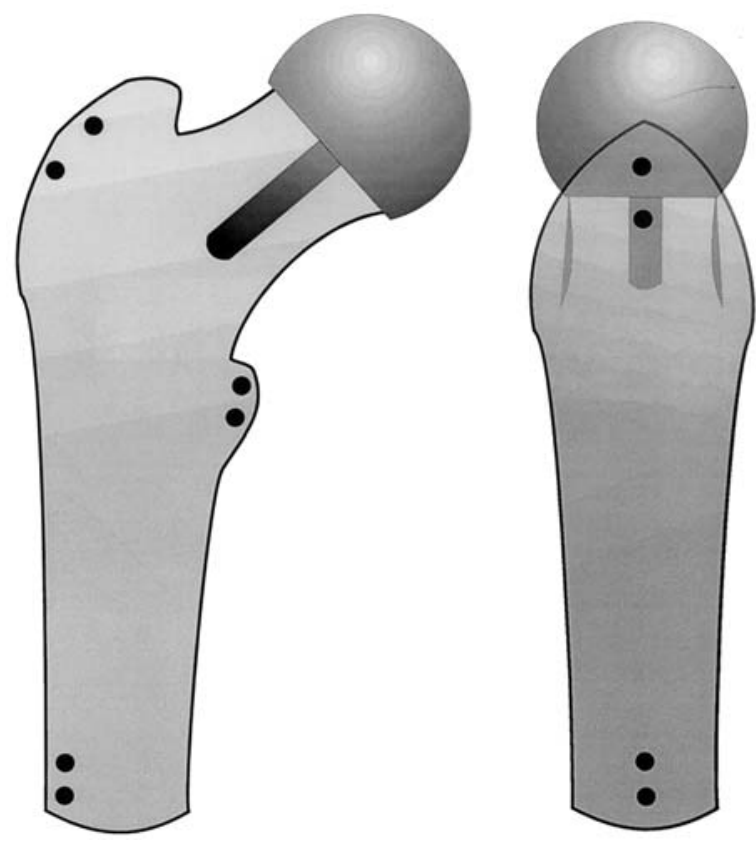

Fig. 1

Diagrams showing the placement of the marker balls around the femoral component.

formed through an extended posterolateral approach with the patient in the lateral decubitus position. CMW3G cement (DePuy, Leeds, UK) was applied beneath the head of the femoral component (the stem being cementless) and the wound was drained in all cases. The patients underwent a routine post-operative rehabilitation programme. There were no failures during this period. Table I gives the details of the patients.

A power calculation was performed before the study using the method of Altman. ${ }^{9}$ A difference of interest of $0.35 \mathrm{~mm}$ was chosen based upon the work of Kobayashi et al, ${ }^{7}$ which suggests that a vertical migration rate of greater than $0.4 \mathrm{~mm}$ is associated with a higher rate of aseptic loosening. A standard deviation of 0.31 was used, a value which was determined from our previous RSA study of the Charnley-Elite stem, ${ }^{8}$ a device which is not designed to subside. The power calculation indicated that a total of 20 subjects was required $(\alpha=0.05, \beta=0.9)$.

RSA was used to measure the migration of the implants. Our RSA technique ${ }^{8}$ is able to measure movements of a marker with an accuracy of $0.1 \mathrm{~mm}$. RSA radiographs were taken with the patient standing with equal weight on both legs immediately after operation and at three, six, 12 and 24 months after surgery. Radiographs were taken at no more than two weeks on either side of the desired time interval. From the RSA images the three-dimensional (3-D) positions of the prosthesis and host bone were reconstructed. By comparing the positions obtained from the post-operative and subsequent radiographs, the 3-D migra- 


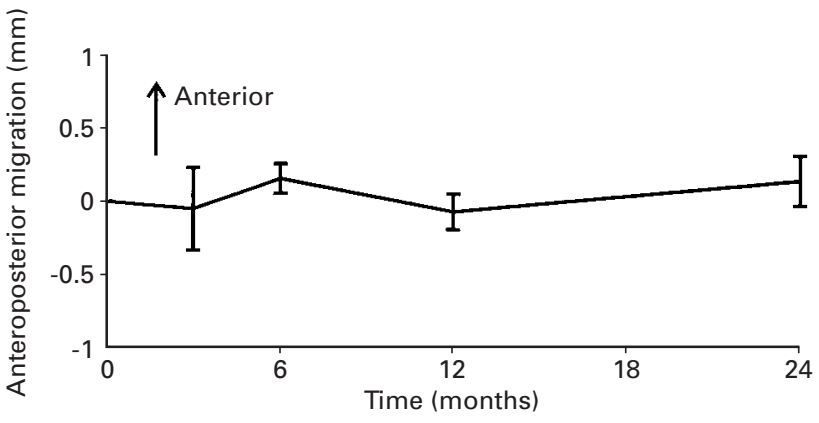

Fig. 2a

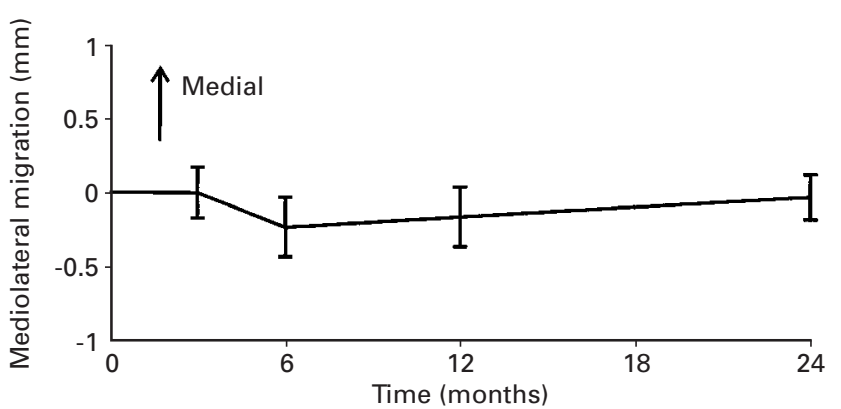

Fig. $2 b$

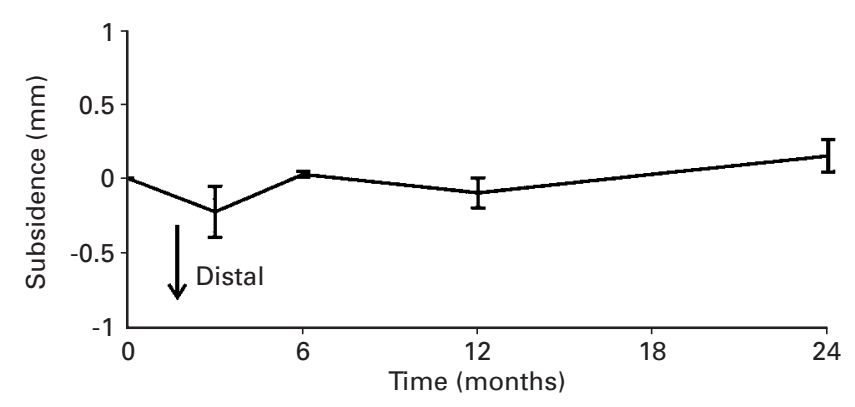

Fig. 2c

Migration of the head during the first two years after surgery showing a) the anteroposterior; b) the mediolateral; and c) the subsidence components of migration. The SEM is represented by error bars.

tion was calculated at three, six, 12 and 24 months after operation. In addition, by comparing the measurements at one and two years, the migration between years one and two was calculated.

As with our previous RSA studies, the host bone was identified by using $0.8 \mathrm{~mm}$ tantalum markers which were placed during the operation at standardised anatomical sites on the femur (Fig. 1). This allowed measurement of the migration of the femoral component. All the femoral markers were placed in cortical bone. Our RSA system checks for movement of the marker ball which is significant over time. Any marker balls with a movement of more than 0.01 $\mathrm{mm}$ in 3-D were automatically excluded. If either exclusion of balls or poor orientation of the subject during radio-

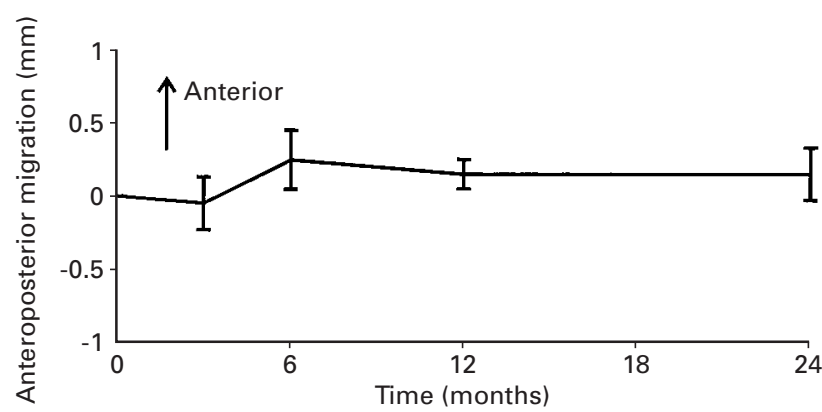

Fig. 3a

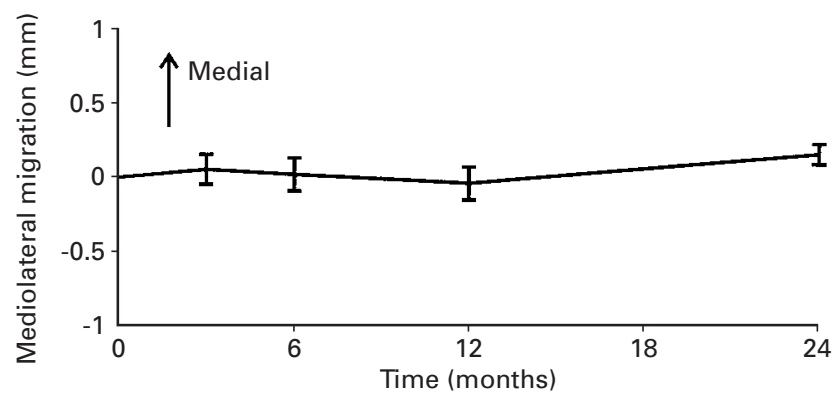

Fig. $3 b$

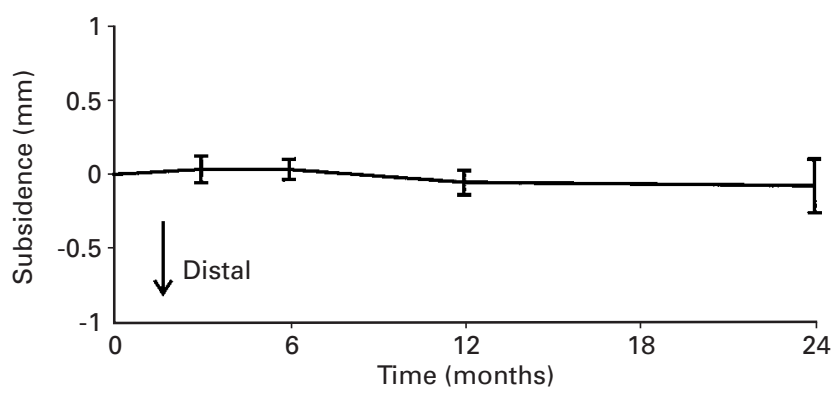

Fig. 3c

Migration of the tip during the first two years after surgery showing a) the anteroposterior; b) the mediolateral; and c) the subsidence components of migration. The SEM is represented by error bars.

graphy resulted in fewer than three well-placed bone markers being visible in the femur, that patient was also excluded from the study. Geometrical algorithms were used to identify the components of the implant and no markers were attached to them.

The total movement of the head and tip was calculated from the length of the 3-D migration vector for each landmark (using $\sqrt{ }\left(x^{2}+y^{2}+z^{2}\right)$, where $x, y$ and $z$ are the Cartesian components of migration.

Statistical analysis. The data were examined for distribution before analysis by using the Shapiro-Wilks test. A $t$-test was used to detect significant deviations of the means from zero. All calculations were performed using SPSS 10 (SPSS Inc, Woking, UK). 
Table II. Migration of the BHR over a period of two years

\begin{tabular}{|c|c|c|c|c|c|c|c|c|c|}
\hline & \multicolumn{3}{|c|}{0 to 1 year } & \multicolumn{3}{|c|}{0 to 2 years } & \multicolumn{3}{|c|}{1 to 2 years } \\
\hline & Mean & $\begin{array}{l}95 \% \\
\mathrm{Cl}^{*}\end{array}$ & $\begin{array}{l}\mathbf{p} \\
\text { value }\end{array}$ & Mean & $\begin{array}{l}95 \% \\
\mathrm{Cl}\end{array}$ & $\begin{array}{l}\mathbf{p} \\
\text { value }\end{array}$ & Mean & $\begin{array}{l}95 \% \\
\mathrm{Cl}\end{array}$ & $\begin{array}{l}\mathbf{p} \\
\text { value }\end{array}$ \\
\hline \multicolumn{10}{|l|}{ Head } \\
\hline Anterior & -0.07 & 0.25 & 0.55 & 0.14 & 0.58 & 0.96 & 0.04 & 0.3 & 0.7 \\
\hline Medial & -0.17 & 0.35 & 0.40 & -0.04 & 0.33 & 0.63 & 0.04 & 0.3 & 0.43 \\
\hline Distal & 0.1 & 0.28 & 0.49 & 0.15 & 0.22 & 0.29 & -0.05 & 0.17 & 0.54 \\
\hline Total & 0.21 & & & 0.21 & & & 0.08 & & \\
\hline \multicolumn{10}{|l|}{ Tip } \\
\hline Anterior & 0.15 & 0.21 & 0.19 & 0.15 & 0.36 & 0.43 & -0.04 & 0.18 & 0.31 \\
\hline Medial & -0.04 & 0.29 & 0.78 & 0.15 & 0.14 & 0.1 & 0.01 & 0.3 & 0.63 \\
\hline Distal & 0.05 & 0.16 & 0.55 & 0.07 & 0.34 & 0.66 & -0.09 & 0.14 & 0.2 \\
\hline Total & 0.16 & & & 0.22 & & & 0.1 & & \\
\hline
\end{tabular}

*95\% confidence interval

\section{Results}

No patient was excluded because of migration of the marker balls. One was lost to follow-up because of failure to attend for radiographs. The measurements from three patients were found to be corrupted due to technical radiographic problems. A total of 22 BHR arthroplasties was therefore studied.

The result of the Shapiro-Wilks test showed that the data were normally distributed $(\mathrm{p}=0.51)$.

The head of the femoral component of the BHR migrated about $0.2 \mathrm{~mm}$ in two years (Table II), most of which occurred in the first year, although this level of migration was not statistically significant $(\mathrm{p}=0.31)$. No significant movements in the anteroposterior (Figs $2 \mathrm{a}$ and $3 \mathrm{a}$ ), mediolateral (Figs $2 \mathrm{~b}$ and $3 \mathrm{~b}$ ) and distal (Figs $2 \mathrm{c}$ and $3 \mathrm{c}$ ) directions were seen for both the head and the tip of the femoral component.

\section{Discussion}

Our RSA study has shown that the total 3-D migration of the BHR femoral component during the first two years after operation was approximately $0.2 \mathrm{~mm}$. This migration was neither statistically nor clinically significant. Importantly, the distal migration was less than $0.4 \mathrm{~mm}$. If this value is exceeded, it increases the likelihood of failure for a conventional stem. ${ }^{7}$ This suggests that the device should function well in the long term and should at least be as reliable as a conventional stemmed arthroplasty in terms of aseptic loosening of the component.

Our findings are supported by early data from a Swedish RSA study ${ }^{10}$ which suggested no significant movement at 12 months. No later studies are yet available from this group. The Swedish group used implants with marker balls attached on pegs to the stem, whereas our system used the prosthesis in its original form (Fig. 4). In order to implant a

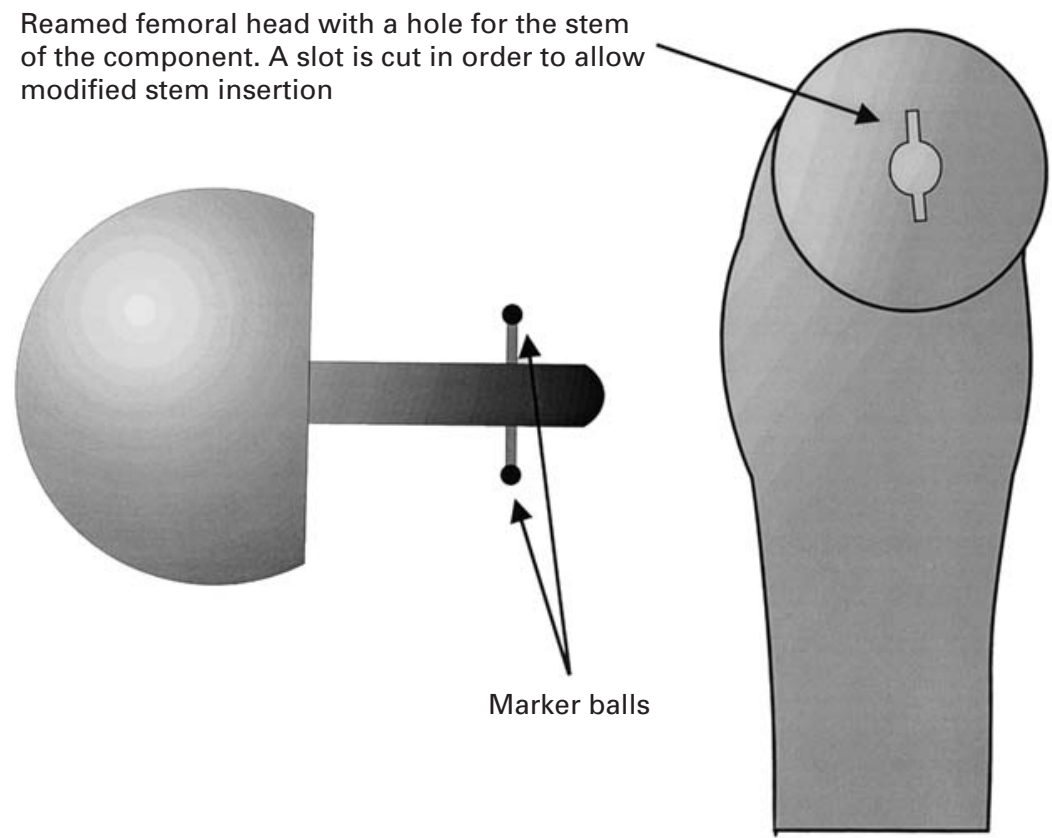

Fig. 4

Diagrams showing the influence of attaching markers to the prosthesis on both the design of the component and the operative procedure as used by the Swedish Group. 
stem with attached marker balls, slots need to be cut into the bone around the stem. Cement will pass down these slots and the stem will become cemented. This contrasts with the standard implant, in which the stem is cementless. RSA data from the modified stem therefore bear little relevance to those obtained with the real prosthesis.

The results of our RSA study of the BHR are encouraging. They suggest that the device is very stable during the first two years after operation. From previous studies, $8,11,12$ it has been demonstrated that stemmed implants subside most within the first year. After this most successful stems migrate at greatly reduced rates for the next five to ten years. Stems which fail prematurely will not show a reduction in the rate of migration at one to two years and will continue at these higher rates until eventual failure. Although migration of the BHR was not statistically significant, it appeared to migrate about $0.2 \mathrm{~mm}$ in total in the first post-operative year and less than $0.1 \mathrm{~mm}$ during the second year. This suggests that it will be stable in the long term. We found that the distal, posterior and total 3-D migration of the head was less than that for any other conventional stem which we have studied, which suggests that the fixation of the BHR stem may be more secure than that of other conventional stems. This is not surprising. The joint contact force acts through the centre of the femoral head. It thus compresses both the bone-cement and implant-cement interfaces of the BHR. These are able to resist compressive loads but not shear loads. With conventional stems the vertical component of the joint contact force acts axially to the stem, ${ }^{13}$ thus generating shear forces at the interface. The posterior component of the joint contact force tends to rotate the stem within the canal. These shear forces may be large, because of the lever arm of the femoral neck and may be one of the main causes of loosening in conventional stems.
The BHR femoral component does not migrate significantly within the first two years after operation. Its migration compares favourably with other designs of femoral component. It is likely to remain stable in the future, since most migration of an implant occurs within the first two years.

The first author was supported by a Royal College of Surgeons Fellowship. No benefits in any form have been received or will be received from a commercial party related directly or indirectly to the subject of this article.

\section{References}

1. Amstutz HC. Innovations in design and technology: the story of hip arthroplasty. Clin Orthop 2000;378:23-30.

2. McMinn D, Treacy R, Link, Pynsent P. Metal on metal surface replacement of the hip: experience of the McMinn prosthesis. Clin Orthop 1996 (329 Suppl):89-98.

3. Ebied A, Journeaux SF, Pope JA. Hip resurfacing arthroplasty: the Liverpool experience. In: Engineers and surgeons: joined at the hip, international conference, 2002. London, UK: IMechE.

4. Watanabe Y, Shiba N, Matsuo S. Biomechanical study of the resurfacing hip arthroplasty: finite element analysis of the femoral component. J Arthroplasty 2000; 15:505-11.

5. Karrholm J, Borssen B, Lowenhielm G, Snorrason F. Does early micromotion of femoral stem prostheses matter: 4-7 year stereoradiographic follow-up of 84 cemented prostheses. J Bone Joint Surg [Br] 1994;76-B:912-7.

6. Mjoberg B, Selvik G, Hansson LI, Rosenquist R, Onnerfalt R. Mechanical loosening of total hip prostheses: a radiographic and roentgen stereophotogrammetric study. J Bone Joint Surg [Br] 1986;68-B:770-4.

7. Kobayashi A, Donnelly WJ, Scott G, Freeman MA. Early radiological observations may predict the long-term survival of femoral hip prostheses. J Bone Joint Surg [Br] 1997;79-B:583-9.

8. Alfaro-Adrian J, Gill HS, Murray DW. Cement migration after THR: a comparison of Charnley Elite and Exeter femoral stems using RSA. J Bone Joint Surg [Br] 1999; 81-B:130-4.

9. Altman DG. Practical statistics for medical research. London: Chapman and Hall, 1999.

10. McMinn D, Pynsent P. Surgical aspects of hip resurfacing. In: Engineers and surgeons: joined at the hip, international conference, 2002. London, UK: IMeche.

11. Alfaro-Adrian J, Gill HS, Marks BE, Murray DW. Mid-term migration of a cemented total hip replacment assessed by radiostereometric analysis. Int Orthop 1999;23:140-4.

12. Alfaro-Adrian J, Gill HS, Murray DW. Should total hip arthroplasty femoral components be designed to subside?: a radiostereometric analysis study of the Charnley Elite and Exeter stems. J Arthroplasty 2001;16:598-606.

13. Bergmann G, Deuretzbacher G, Heller $\mathbf{M}$ et al. Hip contact forces and gait patterns from routine activities. J Biomech 2001;34:859-71. 